\title{
CFD Simulation Studies on Integrated Approach of Solar Chimney and Earth Air Tunnel Heat Exchanger for Building Space Conditioning
}

\author{
Shiv Lal ${ }^{1}$, Subhash Chand Kaushik ${ }^{2}$ \\ ${ }^{1}$ Department of Mechanical Engineering, Rajasthan Technical University, Kota, India \\ ${ }^{2}$ Centre for Energy Studies, Indian Institute of Technology Delhi, New Delhi, India \\ Email address: \\ shivlal1@gmail.com (S. Lal), kaushik@ces.iitd.ac.in (S. C. Kaushik)
}

\section{To cite this article:}

Shiv Lal, Subhash Chand Kaushik. CFD Simulation Studies on Integrated Approach of Solar Chimney and Earth Air Tunnel Heat Exchanger for Building Space Conditioning. International Journal of Economy, Energy and Environment. Vol. 2, No. 3, 2017, pp. $32-39$.

doi: 10.11648/j.ijeee.20170203.11

Received: May 3, 2017; Accepted: May 31, 2017; Published: June 30, 2017

\begin{abstract}
Individual studies on solar chimney and earth air tunnel heat exchanger have been carried out by various researchers but individual systems are not fulfilling the space heating and cooling demand of buildings. So, integrated approach of solar chimney and earth air heat exchanger has been studying in this communication. Computational fluid dynamics software is used for the modelling and simulation studies. The cooling effect is produced by $5.30-6.72 \mathrm{~kW}$ at $40^{\circ} \mathrm{C}$ ambient temperature and space heating is evaluated as $10.28-14.71 \mathrm{~kW}$ at $5^{\circ} \mathrm{C}$ ambient temperature and $400-1000 \mathrm{~W} / \mathrm{m} 216$ solar radiations. And it is sufficient heating and cooling for buildings at average solar irradiance. The SC-EATHE integrated system approach produced 18 37\% higher heating and cooling effect than the EATHE alone system.
\end{abstract}

Keywords: Solar Chimney, Earth Air Tunnel Heat Exchanger, Integrated Approach, Computational Fluid Dynamics (CFD)

\section{Introduction}

In the solar chimney, air is heated through solar heat in a hollow cavity which associated with absorber plate and glass cover. The heated air can be used for space heating via recycling the heated air to the room. The theoretical, experimental and simulation studies of solar chimney have been carried out by, Bansal et al. (1994), Ong (2003), Mathur et al. (2006), Lal et al. (2013), Lal (2014). Bansal et al (2005) studied a solar chimney assisted wind tower for natural ventilation. The effect of solar chimney was estimated and found that, the solar chimney is substantial induced natural ventilation for low wind speed regions. The tilted solar chimney was used in this study. This optimum tilt angle is required to ensure the best tilt angle and it is observed between $40^{\circ}$ to $60^{\circ}$ depending upon the solar angle and latitude \& longitude of the place [Hamdy and Fikary, 1998, Mathur et al. 2006, Bassiouny et al. 2009].

On the other hand earth air tunnel heat exchanger (EATHE) is one of the passive energy options which used to exchange the heat energy between tube air and the ground. The EATHE is buried at 3-4 $\mathrm{m}$ depth in the ground, which is the optimum depth by considering economic [Sharan and Jadhav 2002, 2003]. A tube is buried at a optimum depth in a ground, the ambient air flowing inside the tube and heat exchanges between air and ground, by which, we can obtain the hot and cold air at the exit of the tunnel. Goswami and Biseli (1993) reported that the coefficient of performance (COP) of the Earth air tunnel heat exchanger is higher than the conventional air conditioner system. Trombe and Serres (1994) used a single line of pipe for experimental study by this single line the air may be cooled by $3^{\circ} \mathrm{C}$ from $35 \mathrm{~m}$ long PVC buried pipe. Many researchers developed a theoretical model of earth air tunnel heat exchanger for predicting the outlet temperature, performance analysis and the ground temperature (Bansal and Sodha (1986), Kumar et al. (2003), Ajmi et al. (2006), Wu et al. (2007)). Kumar et al (2003) used the concept of artificial neural network to evaluate the behaviour of the EATHE. It was discussed the length, ambient temperature, ground surface temperature, buried depth and mass flow rate the six parameters which affected the performance of EATHE. Kaushik et al (2014) experimentally studied thermal performance prediction and energy conservation potential of earth air tunnel heat 
exchanger for thermal comfort in Gurgaon India.

Qirong et al. [2011] proposed an integrated approach of Trombe wall, roof solar collector and chimney and investigated the effect of total length and width of chimney on the performance of the system. They reported that the performance of integrated system found better as compared to the single solar chimney. The numerical study also carried out to evaluate the performance parameters for ventilation rate as a function of inclined angle of second floor, length ratio of vertical to inclined, and chimney inclined angle. Maerefat and Haghighi (2010) proposed an integrated approach of solar chimney and earth air tunnel for space cooling and ventilation. It was also designed a $25 \mathrm{~m}$ EATHE for a specific building and two solar chimneys mounted at optimum angle on the top of modelled house. It was presented the simulated results and optimizes the design based on cooling demand. Lal et al. (2012) also proposed various integrated approach of solar chimney and other passive systems for increasing the effect of the system for heating and cooling of buildings.

No experimental data are available in the literature for integrated approach of solar chimney and earth air tunnel heat exchanger. In this communication, integrated approach of solar chimney and EATHE has been used for the study for both cooling and heating of buildings. The performance study of integrated approach is carried out through CFD simulation in present manuscript. The performance study of integrated approach is carried out through CFD simulation in present manuscript.

\section{Analysis of Solar Chimney Integrated with EATHE}

\subsection{Basic Equations for CFD Modelling of Integrated Approach}

Navier-Strokes equation is used to govern the unsteady air flow/steady flow through the earth air tunnel heat exchanger. For air flow through earth air tunnel heat exchanger continuity, momentum and energy equations are given as follows:

Continuity equation

$$
\frac{\partial \rho}{\partial t}+\frac{\partial(\rho u)}{\partial x}+\frac{\partial(\rho v)}{\partial y}+\frac{\partial(\rho w)}{\partial z}=0
$$

$\mathrm{X}$-momentum equation

$\frac{\partial(\rho u)}{\partial t}+\frac{\partial\left(\rho u^{2}\right)}{\partial x}+\frac{\partial(\rho u v)}{\partial y}+\frac{\partial(\rho u w)}{\partial z}=-\frac{\partial \rho}{\partial x}+\frac{1}{R_{e f}}\left[\frac{\partial \tau_{x x}}{\partial x}+\frac{\partial \tau_{x y}}{\partial y}+\frac{\partial \tau_{x z}}{\partial z}\right]$

Y-momentum equation

$$
\begin{gathered}
\frac{\partial(\rho v)}{\partial t}+\frac{\partial(\rho u v)}{\partial x}+\frac{\partial\left(\rho v^{2}\right)}{\partial y}+\frac{\partial(\rho v w)}{\partial z}=-\frac{\partial \rho}{\partial y}+\frac{1}{R_{e f}}\left[\frac{\partial \tau_{x y}}{\partial x}+\frac{\partial \tau_{y y}}{\partial y}+\right. \\
\left.\frac{\partial \tau_{y z}}{\partial z}\right]
\end{gathered}
$$

Z-momentum equation

$$
\frac{\partial(\rho w)}{\partial t}+\frac{\partial(\rho u w)}{\partial x}+\frac{\partial(\rho v w)}{\partial y}+\frac{\partial\left(\rho w^{2}\right)}{\partial z}=-\frac{\partial \rho}{\partial z}+\frac{1}{R_{e f}}\left[\frac{\partial \tau_{x z}}{\partial x}+\frac{\partial \tau_{y z}}{\partial y}+\frac{\partial \tau_{z z}}{\partial z}\right]
$$

Energy equation

$$
\begin{array}{r}
\frac{\partial\left(E_{r}\right)}{\partial t}+\frac{\partial\left(u E_{r}\right)}{\partial x}+\frac{\partial\left(v E_{r}\right)}{\partial y}+\frac{\partial\left(w E_{r}\right)}{\partial z}=-\frac{\partial(u p)}{\partial x}-\frac{\partial(v p)}{\partial y}-\frac{\partial(w p)}{\partial z}- \\
\frac{1}{R_{e f} P_{r f}}\left[\frac{\partial q_{x}}{\partial x}+\frac{\partial q_{y}}{\partial y}+\frac{\partial q_{z}}{\partial z}\right]+\frac{1}{R_{e f}}\left[\frac{\partial\left(u \tau_{x x}+v \tau_{x y}+w \tau_{x z}\right)}{\partial x}+\right. \\
\left.\frac{\partial\left(u \tau_{x y}+v \tau_{y y}+w \tau_{y z}\right)}{\partial y}+\frac{\partial\left(u \tau_{x z}+v \tau_{y z}+w \tau_{z z}\right)}{\partial z}\right]
\end{array}
$$

Transport equations for turbulent kinetic energy $(k)$ and turbulent dissipation energy $(\epsilon)$ are given as follows:

$$
\begin{gathered}
\frac{\partial(\rho k)}{\partial t}+\frac{\partial\left(\rho k u_{j}\right)}{\partial x_{j}}=\frac{\partial}{\partial x}\left[\left(\mu+\frac{\mu_{t}}{\sigma_{k}}\right) \frac{\partial k}{\partial x_{j}}\right]+P_{k}+P_{b}-\rho \epsilon-Y_{M}+ \\
S_{k} \\
\frac{\partial}{\partial t}(\rho \epsilon)+\frac{\partial}{\partial x_{j}}\left(\rho \epsilon u_{j}\right)=\frac{\partial}{\partial x_{j}}\left[\left(\mu+\frac{\mu_{t}}{\sigma_{\epsilon}}\right) \frac{\partial \epsilon}{\partial x_{j}}\right]+\rho C_{1} S_{\epsilon}- \\
\rho c_{2} \frac{\epsilon^{2}}{k+\sqrt{v \epsilon}}-C_{1 \epsilon} \frac{\epsilon}{k} C_{3 \epsilon} P_{b}+S_{\epsilon}
\end{gathered}
$$

Where, the model constants are $P_{k}$ and $P_{b}$ represent the generation of turbulent kinetic energy to the mean velocity gradients and buoyancy. Where, $\epsilon$ is the dissipation, $\mu_{t}$ is eddy viscosity and $\mathrm{t}$ represent the turbulent. Therefore the values of some constants are given as follows:

$$
C_{1}=1.14, C_{2}=1.9, \sigma_{k}=1.0 . \sigma_{\epsilon}=1.2
$$

We consider the Realizable k-epsilon model with the steady turbulent flow so that Reynolds-Averaged Navier-Stokes equations (RANS) are used for simulation with $(k-\varepsilon)$ model.

\subsection{Computational Fluid Dynamic Model Building Ventilation and Space Cooling}

A two Dimensional geometry of solar chimney and EATHE integrated system for space cooling is developed in design modular (DM) associated with ANSYS 14.0 workbench. It is shown in Figure1.

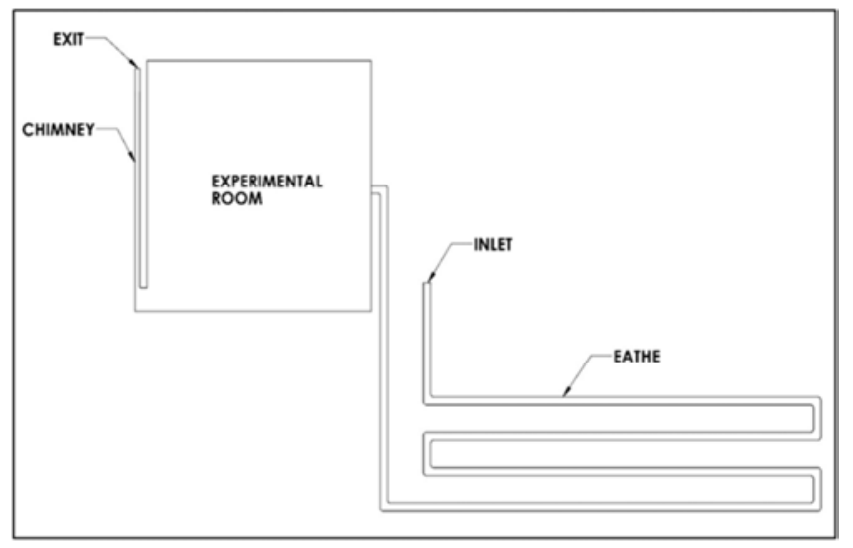

Figure 1. Model of solar chimney and EATHE integration for space cooling.

All zones, domains are dimensioned and defined before updating the model. The glass, black body, and buried pipe 
are defined as solid edge domain whereas the air is defined as fluid surface domain. The model is edited in Meshing software according to the requirement of mesh. The mesh have defined by its size and shape and refined at the important edges. The quality of the mesh plays a direct role on the quality of the analysis, regardless of the flow solver. The final mesh for integrated approach of SC-EATHE is contains 97391 elements and 102508 nodes. The mesh is well defined and uniform throughout the SC-EATHE model other than nearby the surfaces.

The steady $(k-\varepsilon)$ realizable turbulent flow model is considering with standard wall function. Discrete ordinance (DO) model have been used to account the radiation effect in solar chimney. The computational effort is supported by a Work station configured as: make-Dell precision T7400, $800 \mathrm{MHz}$ multicore Intel Xeon processors, 64GB RAM and 1TB HDD. The higher random access memory and fast processor is reducing the simulation time. The meshed model is updated towards the FLUENT. The above mentioned model for CFD calculations have defined and putting all boundary conditions before start the simulation. The simulation is initiated from the inlet point and completed up to the convergence at the end of flow. It will take time to simulate the model. After convergence, the results are obtained in to the tabulated form or as contour format.

\subsection{CFD Modelling of SC-EATHE Integration for Building Space Heating}

Again a two Dimensional geometry of solar chimney and EATHE integrated system of same dimensions for space heating is developed in design modular (DM) associated with ANSYS 14.0 workbench as shown in Figure 2. The zones and domains defined before updating the model to the meshing. The glass, black body buried pipe are defined as solid edge domain whereas the air is defined as fluid surface domain. The model is edited in Meshing software according to the requirement of mesh. The final mesh for integrated approach of SC-EATHE is contains 53823 elements and 57548 nodes. The mesh is well defined and uniform throughout the SC-EATHE model other than nearby the surfaces. A two dimensional steady, Realizable k-epsilon turbulent model with standard wall function and DO (Radiation) used for the simulation study. The important properties of materials and modelling parameters are required for the CFD simulation which is shown in Table (1) given as below.

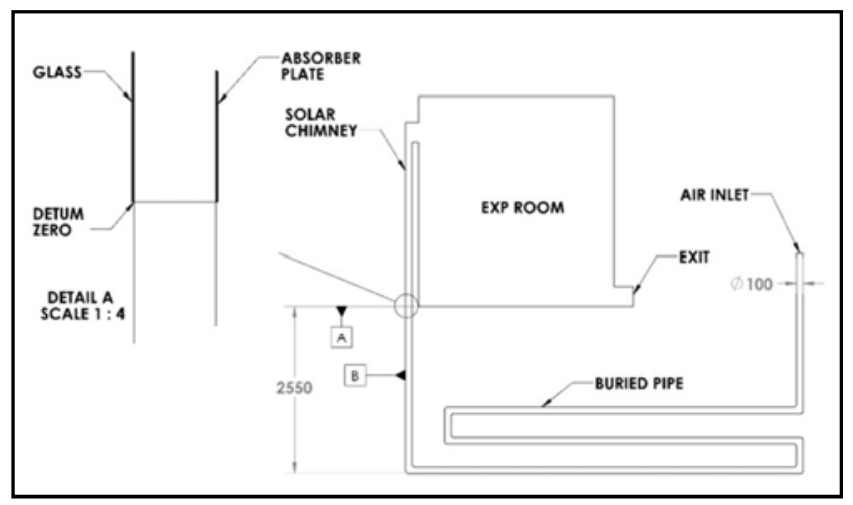

Figure 2. SC-EATHE for space heating.

Table 1. Properties of materials.

\begin{tabular}{llllll}
\hline Material & $\boldsymbol{\rho}, \boldsymbol{k g} / \boldsymbol{m}^{\mathbf{3}}$ & $\boldsymbol{C}_{\boldsymbol{p}} \boldsymbol{J} / \mathbf{k g}^{\circ} \boldsymbol{C}$ & $\boldsymbol{k}, \boldsymbol{W} / \boldsymbol{m}^{\circ} \boldsymbol{C}$ & Emissivity & Absorptivity, $\boldsymbol{\alpha}$ \\
\hline Mild Steel & 7800 & 500 & 52 & 0.95 & 0.95 \\
Glass & 2500 & 820 & 1 & 0.9 & 0.06 \\
Air & 1.225 & 1006.43 & 0.0242 & --- & -0.84 \\
\hline
\end{tabular}

\section{Results and Discussion}

\subsection{Effect of Mass Flow Rate on Building Space Cooling}

The 4 inch diameter $25 \mathrm{~m}$ long earth air tunnel heat exchanger is chosen for the study. In solar chimney, a black painted $0.9 \times 2.54 \mathrm{~m} 2 \mathrm{M}$.S. plate type absorber used with a single glass cover and having equal inlet- outlet vents $(0.30 \times 0.30 \mathrm{~m} 2)$. The $\mathrm{ACH}$ required for comfort conditioning is 3.6; the estimated velocity of air required is $4 \mathrm{~m} / \mathrm{s}$. Therefore $482.22 \mathrm{~W}$ cooling effect has been observed at $500 \mathrm{~W} / \mathrm{m}^{2}$ solar radiations. The effect of air velocity on cooling effect is shown in Figure 3. It is seen that, the cooling effect increases by increases the mass flow rate in earth air tunnel.

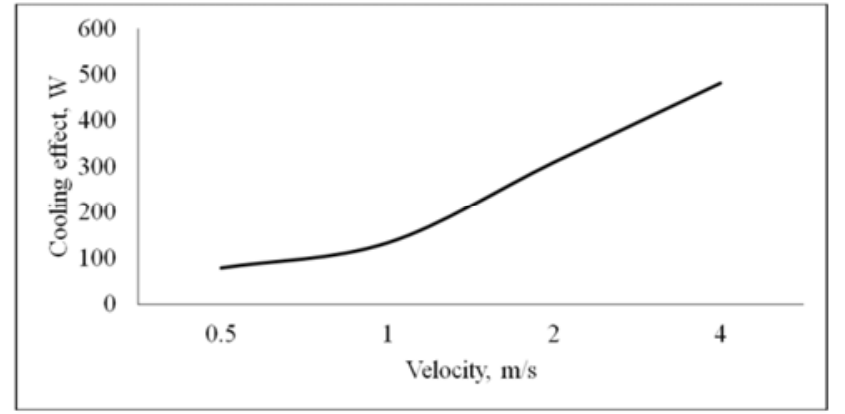

Figure 3. Effect of mass flow rate on building space cooling.

\subsection{Pressure Variation in the Integrated System for Building Space Cooling}

The static pressure contour is shown in Figure4; it is observed that the inlet side pressure is higher than the outlet side in EATHE and similar pattern have been followed by the solar chimney. It is revealed that the velocity is observed 
higher at low pressure area it can be understand by energy conservation equation. The pressure distribution in the room is not uniform.

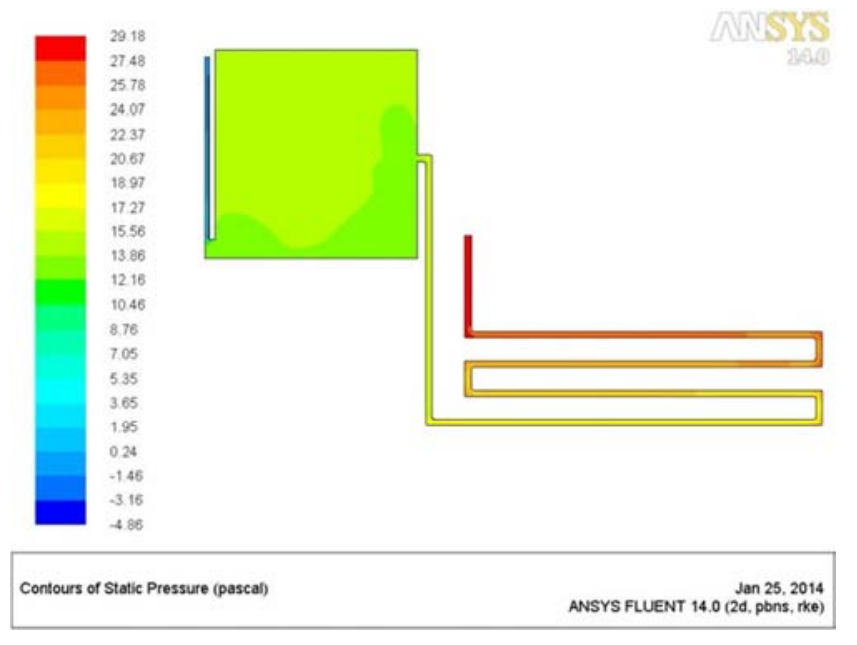

*Jan 25, 2014 is the date of CFD simulation.

Figure 4. Static pressure contour of SC-EATHE in cooling mode.

\subsection{Temperature Variation in the Integrated System for Building Space Cooling}

The Figure5 shows the static temperature contour, it is found that the temperature at inlet of EATHE is higher and air being cooled when it passed through the EATHE.

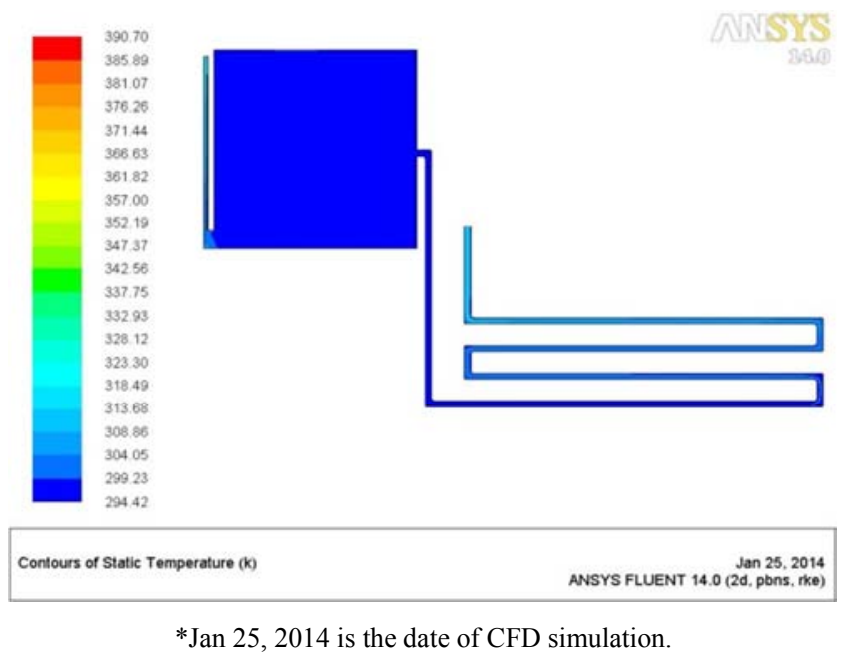

Figure 5. Static temperature contour of SC-EATHE in cooling mode.

The reduction of air temperature is clearly understood by the colour change in this contour. The temperature at the exit of chimney observed higher than the chimney inlet temperature, it creates a suction effect or stack effect to generate the required $\mathrm{ACH}$. The room temperature has been maintained by $27-30^{\circ} \mathrm{C}$ at various solar radiation levels as 400-1000W/m².

The Figure6 shows that the all three temperature as outlet of EATHE and SC along with room temperature increases with increases solar radiation. The room temperature is maintained in comfort zone by the help of EATHE and solar chimney integration.

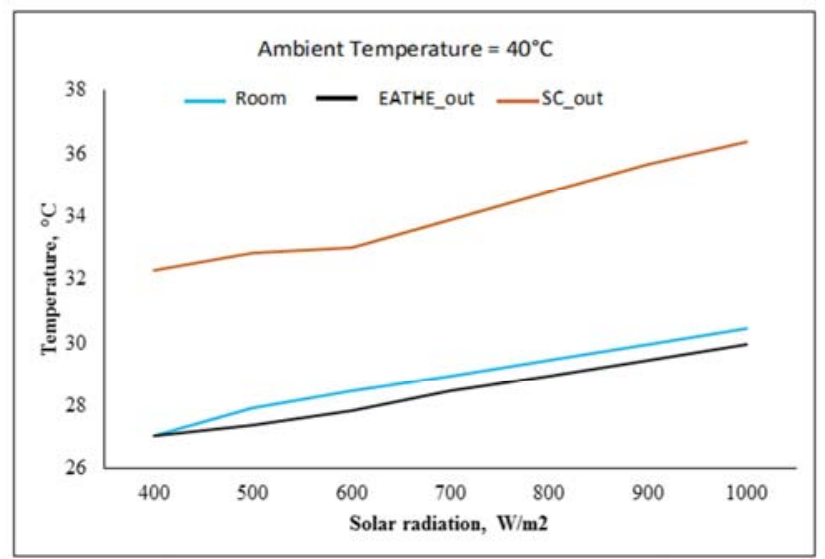

Figure 6. Air outlet and room temperature v/s solar radiation.

\subsection{Velocity Variation in the Integrated System for Building Space Cooling}

The velocity contour shown in Figure7, it is seen that the air velocity is increases as pressure decreases in flow direction. The velocity at exit of EATHE is higher than the inlet and the similar pattern have followed by the solar chimney. A constant velocity has observed in room by $0.42 \mathrm{~m} / \mathrm{s}$, and the air change per hour is obtained by 4 .

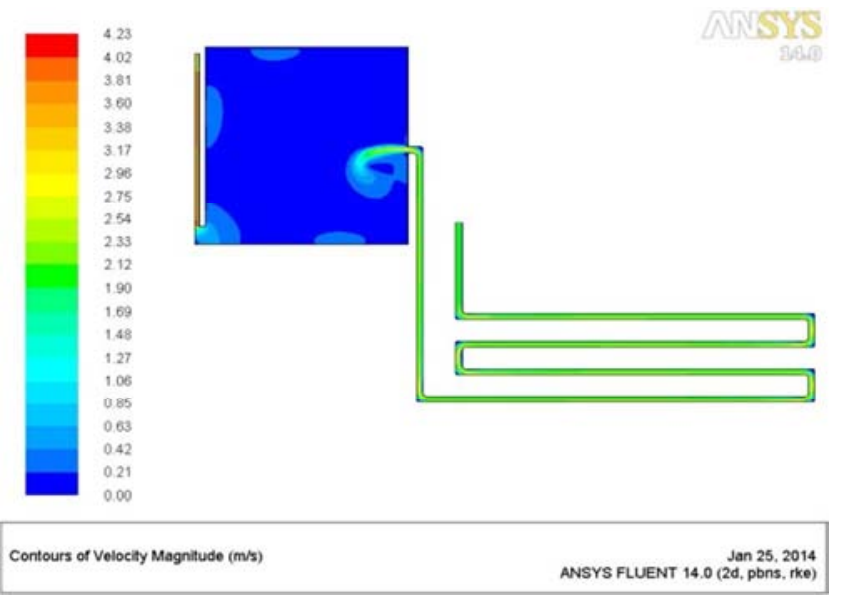

*Jan 25, 2014 is the date of CFD simulation.

Figure 7. Velocity contour of SC-EATHE in cooling mode.

\subsection{Performance of Integrated System for Building Space Cooling}

The performance of integrated approach for cooling mode is presented Table 2. The ACH observed more than 5 and room temperature is maintained by $27-30^{\circ} \mathrm{C}$. It is found in a comfort zone. The cooling potential is decreases when increases the solar radiation at constant ambient temperature. But the ambient temperature is increases by increasing solar radiation. After all the cooling effect increases by increasing ambient temperature or gap between ambient temperature and annual mean average temperature of air. The estimated cooling effect 
found between 5.30-6.72 $\mathrm{kW}$. Table 3 described the number of solar chimney and EATHE requirement for particular cooling demand according to the solar radiation availability. If the cooling demand increases by more than
$6.70 \mathrm{~kW}$, at least two solar chimneys are required for small increment as $70 \mathrm{~W}$ and two EATHE are needed for more cooling demand.

Table 2. Thermal performance of integrated approach at various solar radiations.

\begin{tabular}{|c|c|c|c|c|c|c|c|c|c|}
\hline \multirow{2}{*}{ S. No. } & \multirow{2}{*}{$\begin{array}{l}\text { Solar radiation } \\
\mathrm{W} / \mathrm{m} 2\end{array}$} & \multicolumn{3}{|c|}{ Velocities, $\mathbf{m} / \mathbf{s}$} & \multicolumn{3}{|c|}{ Temperatures, ${ }^{\circ} \mathrm{C}$} & \multirow{2}{*}{$\begin{array}{l}\text { Cooling effect } \\
\mathrm{kW}\end{array}$} & \multirow[t]{2}{*}{$\mathbf{A C H}$} \\
\hline & & $\mathbf{V i}$ & Vo-EATHE & Vo-SC & $\mathbf{T i}$ & To-EATHE & To-SC & & \\
\hline 1 & 400 & 4.00 & 4.71 & 6.42 & 40 & 27.05 & 32.28 & 6.08 & 5.09 \\
\hline 2 & 500 & 4.00 & 5.57 & 7.06 & 40 & 27.92 & 32.84 & 6.71 & 6.02 \\
\hline 3 & 600 & 4.28 & 5.57 & 7.28 & 40 & 28.46 & 33.01 & 6.41 & 6.02 \\
\hline 4 & 700 & 4.28 & 5.57 & 7.58 & 40 & 28.95 & 33.90 & 6.14 & 6.02 \\
\hline 5 & 800 & 4.28 & 5.57 & 7.71 & 40 & 29.45 & 34.78 & 5.86 & 6.02 \\
\hline 6 & 900 & 4.28 & 5.57 & 7.71 & 40 & 29.96 & 35.66 & 5.58 & 6.02 \\
\hline 7 & 1000 & 4.28 & 5.57 & 7.78 & 40 & 30.35 & 36.22 & 5.31 & 6.02 \\
\hline
\end{tabular}

Table 3. System performance at different indoor and outdoor conditions (For Cooling Demand).

\begin{tabular}{|c|c|c|c|c|c|c|c|}
\hline Cooling demand (kW) & $\begin{array}{l}\text { Solar radiation } \\
\left(\mathrm{W} / \mathbf{m}^{2}\right)\end{array}$ & $\begin{array}{l}\text { Length of } \\
\text { EATHE (m) }\end{array}$ & Ambient temp. $\left({ }^{\circ} \mathrm{C}\right)$ & $\mathrm{ACH}$ & Room Temp. $\left({ }^{\circ} \mathrm{C}\right)$ & Number of SC & $\begin{array}{l}\text { Number of } \\
\text { EATHE }\end{array}$ \\
\hline 1 & $400-1000$ & 25 & 40 & $4-6$ & $27-30$ & 1 & 1 \\
\hline 2 & $400-1000$ & 25 & 40 & $4-6$ & $27-30$ & 1 & 1 \\
\hline 3 & $400-1000$ & 25 & 40 & $4-6$ & $27-30$ & 1 & 1 \\
\hline 4 & $400-1000$ & 25 & 40 & $4-6$ & $27-30$ & 1 & 1 \\
\hline 5 & $400-1000$ & 25 & 40 & $4-6$ & $27-30$ & 1 & 1 \\
\hline 6 & $400-1000$ & 25 & 40 & $4-6$ & $27-30$ & 1 & 1 \\
\hline 8 & $400-1000$ & 25 & 40 & $4-6$ & $27-30$ & 1 & 2 \\
\hline
\end{tabular}

\subsection{Performance of the SC-EATHE Integrated System for Building Space Heating}

The solar chimney and EATHE integrated approach can be used for building space heating in very cold regions, where ambient temperature found less than or equal to be $0^{\circ} \mathrm{C}$. In this case of only integrated approach is found to be helpful to achieve a comfort temperature. The Figure 8 shows the temperature contour of integrated system in space heating mode. It is observed that, a low temperature $\left(5^{\circ} \mathrm{C}\right)$ air enters to the system and due to combined heating approach the room can be maintained at $20-24^{\circ} \mathrm{C}$. The combined effect of space heating is clearly exposed in Figure9. Where $25 \mathrm{~m}$ EATHE have been used and $2.54 \mathrm{~m}$ height solar chimney attached at the exit of the EATHE.

EATHE, solar chimney and room temperature increase with increases in ambient temperature, as shown in the Figure10. The solar chimney outlet temperature is always observed higher than the room and EATHE temperatures. The estimation of these temperatures has been carried out at constant solar radiation by $400 \mathrm{~W} / \mathrm{m}^{2}$ (which is average solar radiation).

The performance of integrated approach for building space heating is presented Table 4 . The ACH observed more than 5 and room temperature can be maintained by $27-30^{\circ} \mathrm{C}$ for below $600 \mathrm{~W} / \mathrm{m}^{2}$ solar radiation after that the chimney effect is not required. Only one EATHE will be sufficient in the region, where average annual ambient temperature estimated by more than $25^{\circ} \mathrm{C}$. But solar chimney is required where this average temperature found less than $20^{\circ} \mathrm{C}$. The comfort temperature is depending on the ambient temperature and the wind velocity flow in the geographical region. The heating potential is increases when increases the solar radiation at constant ambient temperature. The estimated heating effect found between $10.28-14.72 \mathrm{~kW}$. Table 5 described the number of solar chimney and EATHE requirement for particular space heating demand according to the solar radiation availability. If the solar radiation is available more than $700 \mathrm{~W} / \mathrm{m}^{2}$ than there is no use of solar chimney because EATHE gives sufficient heating effect and solar chimney increases the room temperature more than $30^{\circ} \mathrm{C}$.

The SC-EATHE integrated system approach produced 33$37 \%$ higher heating effect than the EATHE alone system. But it could not produce any significant cooling effect, because $\mathrm{SC}$ fitted after the room in fluid circuit and the air flow provided by air pump.

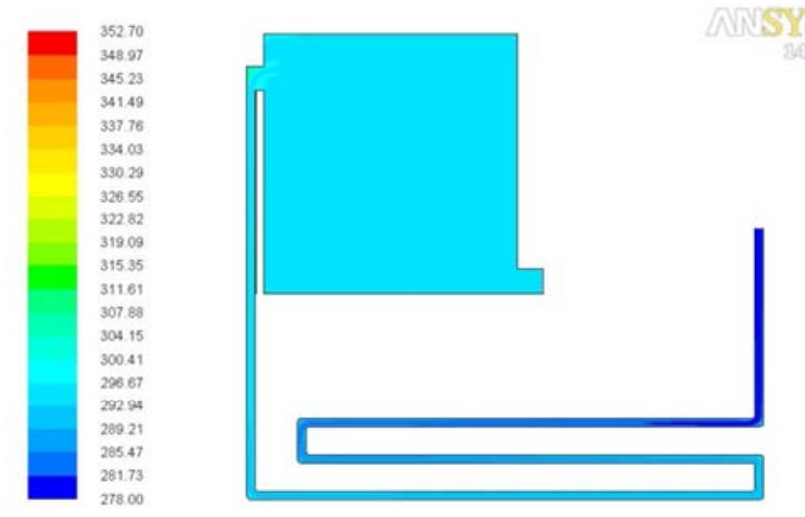

Contours of Static Temperature (k) Jan 27.2014

*Jan 27, 2014 is the date of CFD simulation.

Figure 8. Temperature contour of SC-EATHE integrated system in space heating mode. 


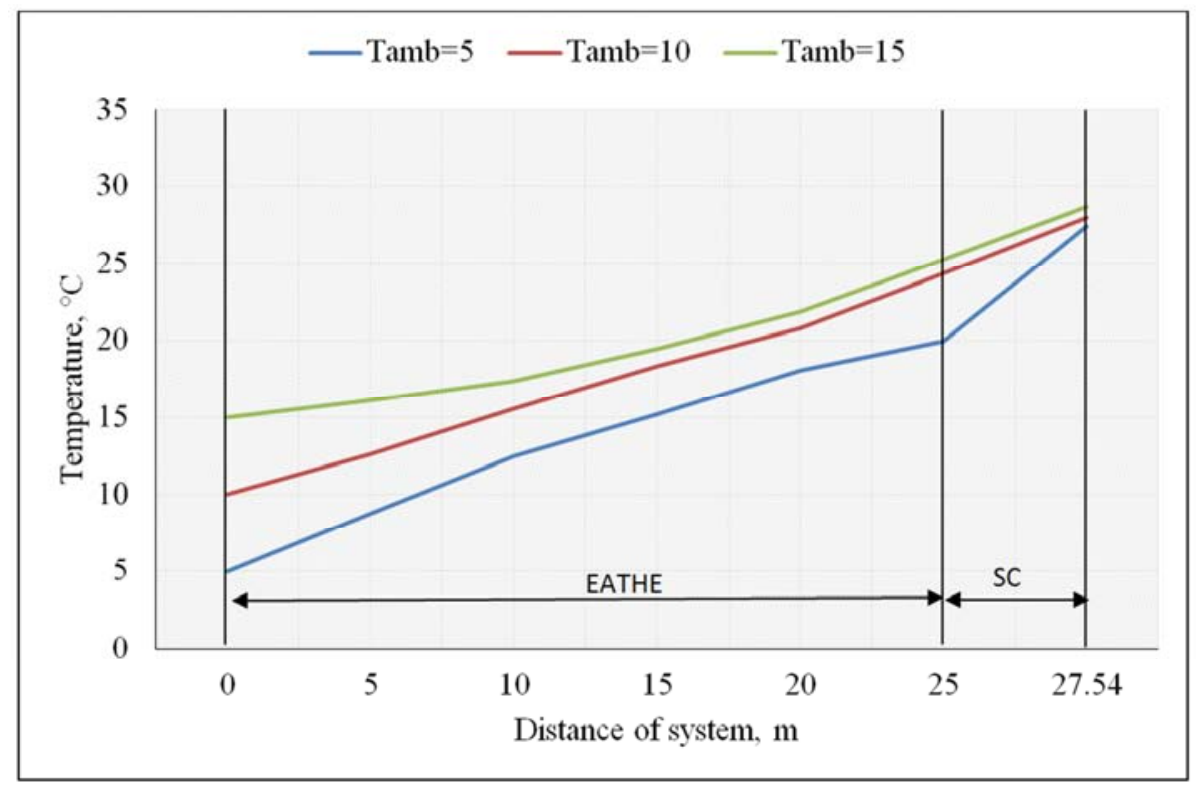

Figure 9. Combined effect of solar chimney and EATHE.

Table 4. Performance of SC-EATHE integration applied for building space heating.

\begin{tabular}{|c|c|c|c|c|c|c|c|c|c|c|}
\hline \multirow{2}{*}{ S. No. } & \multirow{2}{*}{$\begin{array}{l}\text { Solar radiation } \\
\mathrm{W} / \mathrm{m} 2\end{array}$} & \multicolumn{3}{|c|}{ Velocities, $\mathbf{m} / \mathbf{s}$} & \multicolumn{3}{|c|}{ Temperatures, ${ }^{\circ} \mathbf{C}$} & \multirow{2}{*}{$\begin{array}{l}\text { Heating effect } \\
\text { kW }\end{array}$} & \multirow[t]{2}{*}{$\mathrm{ACH}$} & \multirow{2}{*}{$\begin{array}{l}\text { Effect of SC } \\
\% \\
\end{array}$} \\
\hline & & $\mathbf{V i}$ & Vo-EATHE & Vo-SC & $\mathrm{Ti}$ & To-EATHE & To-SC & & & \\
\hline 1 & 400 & 4.00 & 4.34 & 4.63 & 5 & 19.78 & 27.25 & 10.28 & 5.29 & 33.57 \\
\hline 2 & 500 & 4.05 & 4.63 & 4.91 & 5 & 21.04 & 29.14 & 11.83 & 5.36 & 33.55 \\
\hline 3 & 600 & 4.05 & 4.63 & 4.91 & 5 & 22.17 & 30.83 & 12.66 & 5.36 & 33.53 \\
\hline 4 & 700 & 4.05 & 4.63 & 4.91 & 5 & 22.38 & 32.65 & 13.55 & 5.36 & 37.14 \\
\hline 5 & 800 & 4.05 & 4.63 & 4.91 & 5 & 23.42 & 34.21 & 14.32 & 5.36 & 36.94 \\
\hline 6 & 900 & 4.05 & 4.63 & 4.91 & 5 & 24.32 & 34.65 & 14.53 & 5.36 & 34.84 \\
\hline 7 & 1000 & 4.05 & 4.63 & 4.91 & 5 & 24.62 & 35.02 & 14.72 & 5.36 & 34.64 \\
\hline
\end{tabular}

Table 5. System performance at different indoor and outdoor conditions.

\begin{tabular}{llllllll}
\hline $\begin{array}{l}\text { Heating } \\
\text { demand }(\mathbf{k W})\end{array}$ & $\begin{array}{l}\text { Solar radiation } \\
\left(\mathbf{W} / \mathbf{m}^{\mathbf{2}}\right)\end{array}$ & Length of EATHE $(\mathbf{m})$ & Ambient temp. $\left({ }^{\circ} \mathbf{C}\right)$ & ACH & Room Temp. $\left({ }^{\circ} \mathbf{C}\right)$ & Number of SC & $\begin{array}{l}\text { Number of } \\
\text { EATHE }\end{array}$ \\
\hline 1 & $400-1000$ & 25 & $0-15$ & $4-6$ & $27-30$ & 1 & 1 \\
2 & $400-1000$ & 25 & $0-15$ & $4-6$ & $27-30$ & 1 & 1 \\
3 & $400-1000$ & 25 & $0-15$ & $4-6$ & $27-30$ & 1 & 1 \\
4 & $400-1000$ & 25 & $0-15$ & $4-6$ & $27-30$ & 1 & 1 \\
5 & $400-1000$ & 25 & $0-15$ & $4-6$ & $27-30$ & 1 & 1 \\
6 & $400-1000$ & 25 & $0-15$ & $4-6$ & $27-30$ & 1 & 1 \\
7 & $400-1000$ & 25 & $0-15$ & $4-6$ & $27-30$ & 1 & 1 \\
8 & $400-1000$ & 25 & $0-15$ & $4-6$ & $27-30$ & 1 & 1 \\
\hline
\end{tabular}

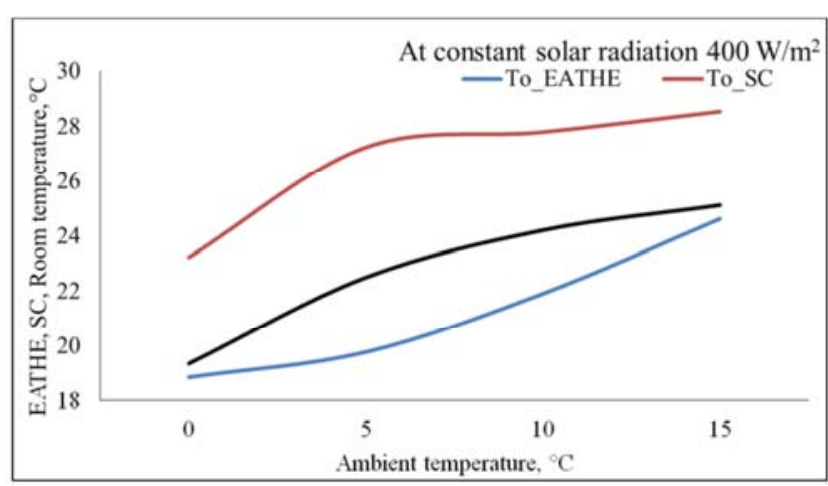

Figure 10. Integrated producing temperatures at different ambient temperature and constant solar radiation.

\section{Conclusions}

The solar chimney and EATHE integrated approach is to be studied for space cooling and heating of building. Two different CFD models has constructed and simulated for various conditions as: for variable solar radiation, variable ambient temperature. The performance of integrated approach also studied for the requirement of solar chimney and EATHE for specified cooling and heating demand. It is concluded that the integrated approach can be used for low temperature regions. The room temperature can be maintained by $27-30^{\circ} \mathrm{C}$, at $5 \mathrm{ACH}$ by this integrated approach in peak summer and winter conditions. The cooling effect is evaluated by $5.30-6.72 \mathrm{~kW}$ at $40^{\circ} \mathrm{C}$ ambient 
temperature and $400-1000 \mathrm{~W} / \mathrm{m}^{2}$ solar radiations. Is the cooling demand increases by more than this limit at least two EATHE will be required to meet out the demand. The space heating is evaluated as $10.28-14.71 \mathrm{~kW}$ at $5^{\circ} \mathrm{C}$ ambient temperature and $400-1000 \mathrm{~W} / \mathrm{m}^{2}$ solar radiations. The SC-
EATHE integrated system approach produced 33-37\% higher heating effect than the EATHE alone system. But it could not produce any significant cooling effect, because SC fitted after the room in fluid circuit and the air flow provided by air pump.

\section{Nomenclature}

$\begin{array}{ll}C & \text { Constant } \\ E & \text { Energy } \\ k & \text { Turbulent kinetic energy } \\ P_{k} & \text { generation of turbulence kinetic energy due to the mean velocity gradients } \\ S_{k} & \text { modulus of the mean rate-of-strain tensor } \\ t & \text { time } \\ u & \text { Velocity component in x-direction } \\ v & \text { Velocity component in y-direction }\end{array}$

$\begin{array}{ll}w & \text { Velocity component in z-direction } \\ Y_{M} & \text { Young's modulus } \\ \epsilon & \text { Turbulent Dissipation } \\ \mu & \text { Viscosity for steady flow } \\ \mu_{t} & \text { Eddy or turbulent viscosity } \\ \rho & \text { Density } \\ \tau & \text { Shear stress }\end{array}$

[11] Sharan G, Jadhav R., 2003. Performance of single pass earthtube heat exchanger: an experimental study. www.builditsolar.com/.../Earth\%20Tubes2003-0107GirjaSharan. pdf, 2003.

[12] Goswami D. Y., Biseli K. M., 1993. Use of underground air tunnel for heating and cooling agricultural and residential buildings. Fact sheet EES 78, University of Florida, pp. 1-4.

[13] Trombe A., Serres, L., 1994. Air-earth exchanger study in real site experimentation and simulation. Energy and Buildings, 21 (2), 155-162. DOI: 10.1016/0378-7788(94) 90008-6.

[14] Bansal, N. K., \& Sodha, M. S., 1986. An earth-air tunnel system for cooling buildings. Tunnelling and Underground Space Technology, 1 (2), 177-182. DOI: 10.1016/08867798(86) 90057-X

[15] Kumar, R., Ramesh, S., and Kaushik, S. C., 2003. Performance evaluation and energy conservation potential of earth-air-tunnel system coupled with non-air-conditioned building. Building and Environment, 38 (6), 807-813. DOI: 10.1016/S0360-1323(03) 00024-6.

[16] Ajmi F. Al. LOveday D. L., Hanby V. I., 2006. The cooling potential of earth air heat exchanger for domestic building in a desert climate. Building and Environment, 3, 235-244.

[17] Wu H., Wang S., Zhau D., 2007. Modelling and evaluation of cooling capacity of earth air pipe systems. Energy conversion and management, 48, 1462-1470.

[18] Kaushik S. C., Garg T., Lal S., 2014. Thermal performance prediction and energy conservation potential of earth air tunnel heat exchanger for thermal comfort in India. Journal of renewable and sustainable energy, 6: 1-12, DOI: 10.1063/1.4861782.

[19] Wei, D., Qirong, Y. and Jincui, Z., 2011. A study of the ventilation performance of a series of connected solar chimneys integrated with building. Renewable Energy, Vol. 36 No. 1, pp. 265-271.

[20] Maerefat, M. and Haghighi, A. P., 2010. Natural cooling of stand-alone houses using solar chimney and evaporative cooling cavity, Renewable Energy, Vol. 35 No. 9, pp. 20402052. 
[21] Shiv Lal, S C Kaushik P K Bhargava. 2012. A study on stack ventilation system and integrated approaches. Emerging trends of energy conservation in buildings, CBRI, India, November $1-3,2012$, pp. 255-263.
[22] ANSYS workbench 14.0, ANSYS, Inc. Canonsburg, Pennsylvania, U. S. A..

[23] http://www.cfd-online.com/Wiki/Standard_k-epsilon_model (Retrieved on 03 January 2014). 